\title{
Investimento público em educação fundamental e a qualidade do ensino: uma avaliação regional dos resultados do Fundef*
}

\author{
Rogério Sobreira** \\ Bruno Cesar Campos***
}

Sumário: 1. Introdução; 2. Aspectos legais e fundamentos econômicos do Fundef; 3. Primeiros resultados do Fundef; 4. Indicadores de qualidade do ensino público fundamental; 5. Financiamento da educação e aprimoramento do ensino; 6. Considerações finais.

Summary: 1 . Introduction; 2. Fundef's legal aspects and economic fundamentals; 3. Fundef's first results; 4. Education funding and the quality of basic education in public schools; 5. Education funding and learning improvement; 6. Final remarks.

Palavras-chave: Fundef; financiamento da educação; ensino fundamental.

KEY WORDs: Fundef; education funding; basic education.

Desde 1998, o financiamento da educação pública fundamental no Brasil está submetido a critérios de vinculação de receitas governamentais regulamentados pelo Fundef (Fundo de Manutenção e Desenvolvimento do Ensino Fundamental e de Valorização do Magistério). Entre os objetivos do fundo está o de garantir recursos mínimos para o investimento público em educação fundamental, assegurando a qualidade do ensino oferecido e, por conseguinte, a melhora na proficiência dos alunos. Com base nos dados de volume de recursos investidos no ensino fundamental via Fundef e nos resultados das Saebs (sinopses estatísticas da educação básica), este artigo analisa os efeitos dessa política pública sobre o desempenho dos alunos da

\footnotetext{
* Artigo recebido em jan. 2006 e aceito em jul. 2007.

** Professor-adjunto da Escola Brasileira de Administração Pública e de Empresas da Fundação Getulio Vargas (Ebape/FGV). Endereço: Praia de Botafogo, 190, sala 517 - CEP 22250-900, Rio de Janeiro, RJ, Brasil. E-mail: rogerio.sobreira@fgv.br.

$* * *$ Mestre em economia pela Universidade Federal Fluminense (UFF) e economista da Petrobras. Endereço: Praia de Botafogo, 190, sala 517 - CEP 22250-900, Rio de Janeiro, RJ, Brasil. E-mail: camposbc@yahoo.com.br.
} 
rede pública de ensino fundamental brasileira. Os resultados apontam a importância do aporte financeiro e da qualificação do magistério para o aperfeiçoamento da qualidade da educação pública.

Public funding for basic education and the quality of learning: a regional assessment of the results from Fundef

Since 1998, public funding for basic education in Brazil has been organized by the Fund for Maintenance and Development of Basic Education and Teaching Valorization (Fundef). One of the goals of this fund is to assure resources for basic education public funding, guaranteeing its quality and thus the improvement of student proficiency. This article analyzes the effects of Fundef in student performance utilizing public data from the fund and from Saeb (basic education statistics synopsis). The results suggest that financial support and teacher qualification are important for the improvement of public education.

\section{Introdução}

O planejamento de políticas educacionais - como o planejamento de qualquer política pública - é uma matéria sujeita a constantes revisões e ajustes, decorrentes da limitada capacidade dos entes governamentais de prever, com exatidão, cenários econômicos num horizonte de tempo muito amplo. Contudo, a demarcação de diretrizes para se contornar atrasos históricos do programa educacional brasileiro, que emperram o desenvolvimento econômico, é imprescindível e justifica o planejamento público.

O Fundo de Manutenção e Desenvolvimento do Ensino Fundamental e de Valorização do Magistério (Fundef) é mais uma entre as políticas públicas para modernizar a educação no país, no longo prazo. Estipulando padrões de financiamento para o sistema educacional, essa legislação garante a manutenção dos recursos para o segmento, além de primar pela diminuição das desigualdades regionais, tão presentes no setor.

Em vigência desde 1998, já é possível traçar alguns primeiros resultados do fundo, checando sua efetividade como instrumento de aprimoramento dos indicadores quantitativos e qualitativos da educação no país. Mesmo apresentando evolução positiva na quantidade de recursos voltados para a educação, o Fundef esteve longe de garantir patamares mínimos desejados em diversos estados. Sobretudo nas regiões mais pobres do país, é possível perceber que os gastos médios anuais por aluno do ensino fundamental ainda são muito baixos, sobretudo quando comparados internacionalmente (Campos e Sobreira, 2005). 
Quando se trata de elementos subjacentes ao aprendizado, a situação das redes estaduais e municipais de ensino fundamental no Brasil é bastante crítica. Facilidades como acesso a uma biblioteca, computadores, laboratórios, entre outros, são privilégios para uma minoria dos alunos, mesmo nas regiões mais prósperas do país. ${ }^{1}$ Por conseguinte, permanecem não apenas as disparidades inter-regionais na qualidade da educação, mas também uma defasagem dos desempenhos anotados entre os alunos das redes pública e privada no país.

Partindo dessas considerações, este artigo avalia qual tem sido o impacto do Fundef sobre as variáveis que mensuram a qualidade da educação pública fundamental ofertada no país. Para tanto, a pesquisa lança mão de dados acerca do fundo, disponibilizados pela Secretaria do Tesouro Nacional, e os confronta com estatísticas de desempenho do alunado disponibilizadas pelo Instituto Nacional de Estudos e Pesquisas Educacionais Anísio Teixeira (Inep). Especificamente, são analisados os resultados das Saeb (sinopses estatísticas da educação básica). Tais sinopses consistem em avaliações bianuais do desempenho dos alunos em provas de língua portuguesa e matemática, permitindo uma comparação inter-regional da qualidade da educação no Brasil.

$\mathrm{O}$ artigo está dividido em seis seções. A seção 2 apresenta traços gerais do mecanismo de funcionamento do Fundef, importantes para uma melhor compreensão da avaliação que se pretende engendrar. A seção 3 traz um panorama dos resultados econômicos do Fundef no período 1998-2003. A seção 4 apresenta alguns dados das Saeb, com a evolução do desempenho do alunado em período correspondente. A quinta seção apresenta uma modelagem econométrica que testa a importância do aporte financeiro e da qualificação do magistério - atributos diretamente relacionados ao Fundef — sobre a proficiência dos alunos das redes públicas de ensino fundamental no Brasil.

\section{Aspectos legais e fundamentos econômicos do Fundef}

A descentralização da gerência dos recursos destinados à educação remete aos anos 1980, num primeiro momento com a Emenda Calmon, que significou um esforço seminal de vinculação de determinados impostos aos gastos educacionais. Mais tarde, com a promulgação da Constituição de 1988 (Brasil, 1995), tal processo tornou-se mais nítido, reflexo da democratização, que exigia uma maior autonomia de entes subnacionais na gestão dos recursos governamentais.

\footnotetext{
${ }^{1}$ Para mais detalhes, consultar <www.inep.gov.br/edudatabrasil $>$.
} 
A criação do Fundef na década de 1990 exprime, assim, uma consolidação das tendências à descentralização do gerenciamento da educação. Por trás dessa proposta subentende-se o intuito de imprimir uma maior visibilidade na gestão orçamentária e financeira dos recursos destinados ao ensino fundamental, conclamando, também, um maior envolvimento dos cidadãos no acompanhamento das questões concernentes ao fundo.

Assim, pode-se dizer que o foco principal da emenda constitucional que o criou esteve voltado muito mais para a correção dos desníveis estruturais do que para as propostas de ampliação dos recursos já existentes. Levando-se em conta as diferentes capacidades de arrecadação tributária e de investimento na área educacional dos diversos estados e municípios, o objetivo era estabelecer parâmetros para a gestão descentralizada dos recursos para o ensino fundamental no país. Além de incidir sobre a forma de gestão das receitas tributárias, o Fundef interferiria também na aplicação dos recursos advindos de transferências intergovernamentais. O fundo é constituído por pelo menos $15 \%$ das seguintes fontes de receitas governamentais: ${ }^{2}$

v Fundo de Participação dos Estados (FPE);

- Fundo de Participação dos Municípios (FPM);

v imposto sobre circulação de mercadorias e serviços (ICMS);

v recursos relativos à desoneração de exportações, objetos da Lei Complementar no

v imposto sobre produtos industrializados, proporcional às exportações (IPI-exp).

O Fundef atua no âmbito das unidades federadas, isto é, a soma de todos os recursos é dividida entre as respectivas administrações estaduais e municipais, obedecendo a critérios de distribuição do número de matrículas, reduzindo, assim, os descompassos entre o volume de verbas disponível e a magnitude das responsabilidades de cada jurisdição. As transferências de recursos entre as esferas estaduais e municipais ocorrem apenas dentro da mesma unidade federativa, não havendo, portanto, repasses de uma unidade para outra.

A meta de valorização do magistério é contemplada na medida em que a legislação obriga que no mínimo $60 \%$ de todo o montante disponibilizado

\footnotetext{
${ }^{2}$ Constitucionalmente, o percentual de receitas a ser vinculado aos gastos em educação pública é de $25 \%$, incluindo todos os níveis de ensino. A legislação do Fundef obriga que o ensino fundamental abarque $60 \%$ dessa vinculação, portanto $15 \%$ das receitas.
} 
pelo Fundef seja aplicado na remuneração do professorado. Além dos professores do ensino fundamental regular, essa fração de recursos também pode ser destinada ao pagamento de profissionais ligados à educação especial, indígena e supletiva ${ }^{3}$ (Brasil, 2004).

O Fundef inclui ainda recursos federais destinados aos estados cujo gasto aluno/ano ${ }^{4}$ fica abaixo de um valor mínimo preestabelecido que, por sua vez, é estipulado anualmente por decreto presidencial e deve levar em conta os resultados do censo escolar e de estimações das receitas tributárias e de transferências destinadas à educação, incluindo recursos no âmbito dos governos estadual e municipal. $\mathrm{O}$ valor necessário para que as unidades federadas mais carentes atinjam o gasto anual mínimo por aluno é repassado pelo governo federal a fundo perdido (Negri, 1997a e b). Importante ressaltar que tal gasto mínimo não necessariamente corresponde ao valor efetivamente aplicado por aluno na educação pública fundamental, podendo representar um valor potencial ou mínimo, dependendo da disponibilidade de receitas em cada estado.

A redação do art. 6o da Lei $\mathrm{n}^{\circ} 9.424$ sugere que o decreto presidencial que determina o valor per capita mínimo teria como parâmetro a média nacional (Brasil, 1996). Consta no texto que esse valor nunca seria inferior ao quociente entre as receitas previstas para o Fundef e as matrículas totais do ensino fundamental no ano anterior, acrescidas das estimações de novas matrículas. O presidente teria que determinar um gasto aluno/ano mínimo pelo menos equivalente a esse quociente, configurando uma política de caráter redistributivo, que garantiria um patamar básico de qualidade no ensino fundamental oferecido no Brasil.

O quadro 1 sintetiza as responsabilidades de cada ente governamental, explicitando também alguns critérios para o rateio das verbas do Fundef.

\section{Primeiros resultados do Fundef}

Por meio da tabela 1 é possível notar que o total de recursos disponíveis para o Fundef em todo o Brasil (a preços constantes de 2003$)^{5}$ supera a casa de $\mathrm{R} \$$

\footnotetext{
${ }^{3}$ Até 2001, a Lei no 9.424/96 possibilitava que essa parcela de recursos também fosse direcionada para despesas com a capacitação de professores leigos.

${ }^{4} \mathrm{O}$ valor do gasto aluno/ano é dado pelo quociente entre o total de receitas tributárias e de transferências destinadas ao Fundef e o total de alunos da respectiva unidade federativa.

${ }^{5}$ Para a conversão dos dados em preços constantes de 2003 foi utilizado o índice de preços ao consumidor amplo (IPCA), fornecido pelo Instituto Brasileiro de Geografia e Estatística (IBGE). Tal escolha se justifica por se tratar do índice de preços oficial do governo.
} 
20 bilhões, estando a maioria dos recursos concentrada na região Sudeste, conforme era de se esperar. Dos seis anos analisados, não houve alteração no ordenamento hierárquico dessa distribuição.

$$
\text { Quadro } 1
$$

Responsabilidades por fontes de financiamento e formas de distribuição do Fundef

\begin{tabular}{|c|c|c|}
\hline Responsável & Fontes de financiamento & Fundo de distribuição \\
\hline União & $\begin{array}{l}\text { Do salário-educação } \\
\text { 18\% das receitas de impostos } \\
\text { devidos à União } \\
\text { - Outras fontes } \\
\text { Seguro-receita da Lei } \\
\text { n } 87 / 96 .\end{array}$ & $\begin{array}{l}\text { A União, de acordo com o } \S 3^{\circ} \text { da } \\
\text { EC n } n^{2} 14 / 96 \text {, complementará os } \\
\text { recursos do fundo sempre que, em } \\
\text { cada estado e no } D F \text {, seu valor por } \\
\text { aluno não alcançar o mínimo definido } \\
\text { nacionalmente. }\end{array}$ \\
\hline Estados e DF & $\begin{array}{l}\text { e } \geq 15 \% \text { do ICMS devido ao DF } \\
\text { aos estados, conforme o que } \\
\text { dispõe o art. 155, inciso II, da } \\
\text { Constituição Federal. }\end{array}$ & $\begin{array}{l}\text { Distribuidos entre os estados e seus } \\
\text { respectivos municipios, proporcionalmente } \\
\text { ao número de alunos matriculados } \\
\text { nas respectivas redes de ensino }\end{array}$ \\
\hline & $\begin{array}{l}\text { v } \geq 15 \% \text { do FPE, previsto no art. } \\
159 \text {, inciso I, alínea } a \text { da Constituição } \\
\text { Federal e no Sistema Tributário Nacional } \\
\text { de que trata a Lei ñ } 5.172 \text {, de } 25 \text { de } \\
\text { outubro de } 1966 \text {. } \\
\text { v } \geq 15 \% \text { do FPEX, que é a parcela do IPI } \\
\text { devida aos estados e ao DF, na forma } \\
\text { do art. } 159 \text {, inciso II, da Constituição } \\
\text { Federal e da Lei Complementar } n^{2} 61 \text {, } \\
\text { de } 26 \text { de dezembro de } 1989 \text {. }\end{array}$ & $\begin{array}{l}\text { - } \geq 60 \% \text { da receita do Fundef será } \\
\text { destinada ao pagamento de professores } \\
\text { do ensino fundamental em efetivo } \\
\text { exerćício no magistério. Nos primeiros } \\
\text { cinco anos, pôdese utilizar parte desses } \\
\text { recursos para a capacitação de } \\
\text { professores leigos. }\end{array}$ \\
\hline Municípios & $\begin{array}{l}\text { v } \geq 15 \% \text { do ICMS devido aos municípios, } \\
\text { conforme o que dispōe o art. } 158 \text {, } \\
\text { inciso IV, da Constituição Federal. } \\
\text { v } \geq 15 \% \text { do FPM, previsto no art. } \\
159 \text {, inciso I, alinea b, da Constituição } \\
\text { Federal e no Sistema Tributário Nacional } \\
\text { de que trata a Lei n } 5.172 \text {, de } 25 \text { de } \\
\text { outubro de } 1966 .\end{array}$ & \\
\hline
\end{tabular}

Fonte: Castro, 1998:11.

A taxa real de crescimento anual dos recursos do fundo para o intervalo 1998-2003 é representada na figura. O gráfico destaca a região Centro-Oeste como a que apresentou taxas reais de crescimento anual iguais ou superiores 
Tabela 1

Total de recursos do Fundef: Brasil e grandes regiões, 1998-2003

\begin{tabular}{|lrrrrrr|}
\hline $\begin{array}{l}\text { Brasil/ } \\
\text { Grande região }\end{array}$ & 1998 & \multicolumn{1}{c}{1999} & 2000 & \multicolumn{1}{c}{2001} & 2002 & \multicolumn{1}{c|}{2003} \\
\hline Brasil & $20.253,65$ & $21.531,06$ & $23.293,49$ & $24.561,33$ & $25.024,46$ & $25.175,29$ \\
Norte & $1.676,93$ & $1.731,50$ & $1.910,20$ & $2.024,26$ & $2.155,05$ & $2.186,37$ \\
Nordeste & $4.747,92$ & $5.129,52$ & $5.374,32$ & $5.609,54$ & $5.886,06$ & $5.713,18$ \\
Sudeste & $9.629,41$ & $10.252,76$ & $11.248,95$ & $11.691,52$ & $11.566,39$ & $11.475,68$ \\
Sul & $3.105,65$ & $3.175,87$ & $3.373,80$ & $3.777,24$ & $3.893,93$ & $4.150,90$ \\
Centro-Oeste & $1.093,74$ & $1.241,42$ & $1.386,22$ & $1.458,77$ & $1.523,02$ & $1.649,16$ \\
\hline
\end{tabular}

Fonte: Secretaria do Tesouro Nacional, IBGE. Elaboração própria.

à taxa brasileira, ao longo de todos os anos analisados. Possíveis explicações desse fato podem incluir o aumento da arrecadação tributária na região, que vem demonstrando grande dinamismo econômico decorrente, sobretudo, do bom desempenho do agronegócio nos últimos anos.

As taxas de crescimento da região Norte também superam as nacionais a partir de 2000, porém, em patamares mais modestos. A região Sul demonstrou comportamento instável, todavia, com taxas superiores às brasileiras a partir de 2001. Já o desempenho da região Sudeste esteve abaixo do nacional a partir do mesmo ano, chegando a apresentar taxas de crescimento reais negativas a partir de 2002 .

Já a região Nordeste apresentou, durante boa parte do tempo (2000, 2001 e 2003), taxas de crescimento anuais abaixo da média nacional. Essa região apresenta as piores performances relacionadas aos indicadores do Fundef, reunindo a maioria dos estados beneficiários do complemento da União ao fundo, justamente por não atingirem o gasto aluno/ano mínimo. ${ }^{6}$ As taxas de crescimento apontadas no gráfico sinalizam, assim, para a manutenção — ou mesmo agravamento - dessa disparidade regional.

A tabela 2 traz a evolução das receitas do Fundef por unidade federativa, além das grandes regiões. Embora a figura tenha mostrado oscilações negati-

\footnotetext{
${ }^{6}$ Até o ano 2000, as únicas unidades federativas do Nordeste que não receberam a complementação da União foram Sergipe e Rio Grande do Norte. Paraíba e Pernambuco deixaram de recebê-la em 2001. Alagoas e Ceará o fizeram, respectivamente, em 2002 e 2003.
} 
vas em períodos determinados, percebe-se que todos os estados apresentaram variação real positiva no total de recursos investidos no ensino fundamental, via Fundef, pelo menos quando se comparam os dois períodos extremos. Os estados que mais se destacaram por apresentarem variação percentual e taxa de crescimento médio anual bem acima da média nacional foram: Acre, Rondônia, Tocantins, Goiás, Mato Grosso e Mato Grosso do Sul. Na maioria dos casos, o bom desempenho se deu em decorrência do aumento na arrecadação do ICMS.

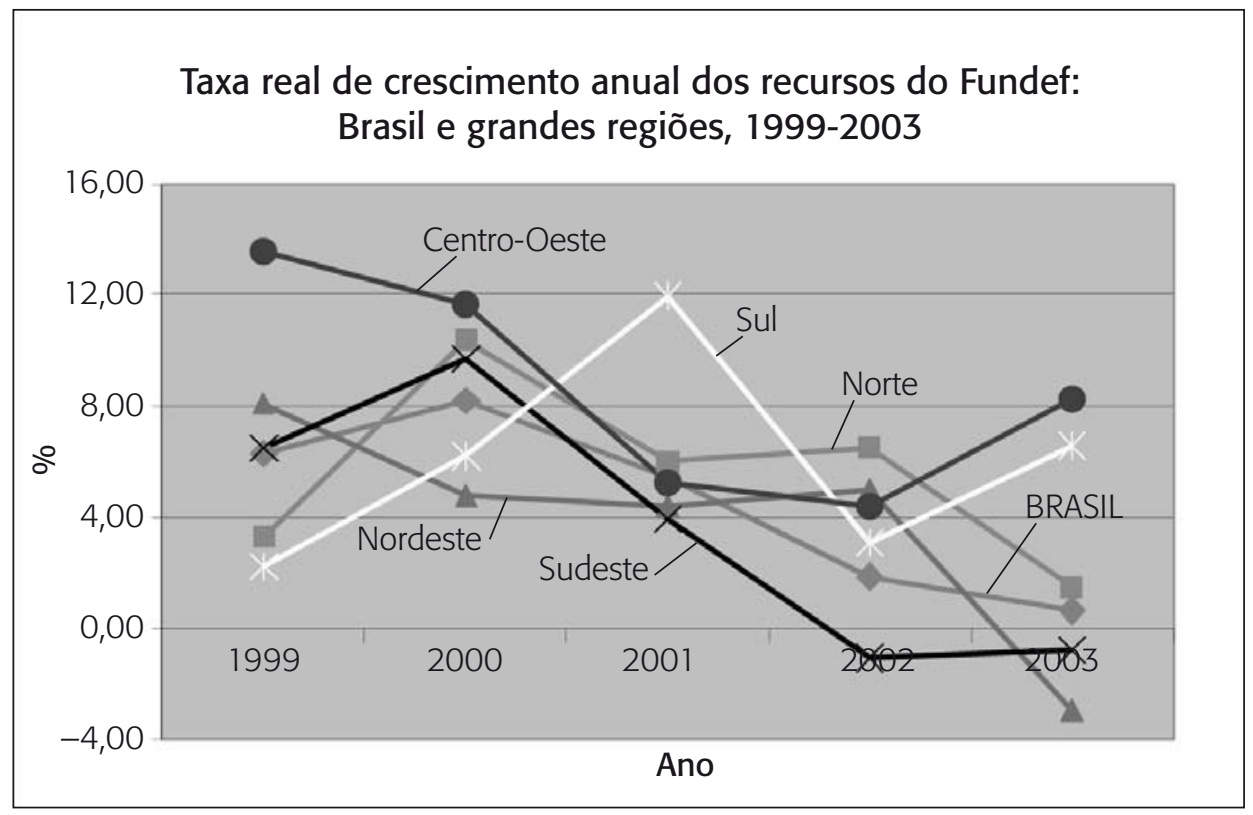

Do lado oposto, os estados com pior desempenho ao longo dos anos foram Pará e Pernambuco, com variação percentual 10 pontos abaixo da média nacional. Nesses casos, o fiel da balança foi representado pelos recursos procedentes do imposto sobre produtos industrializados proporcional às exportações, da Lei Complementar no $87 / 96$ e do complemento da União.

Esse quadro já é suficiente para demonstrar o êxito do fundo no sentido de garantir que o investimento público em ensino fundamental seja compatível com o desempenho econômico e tributário de cada estado brasileiro. A vinculação das receitas garante certa estabilidade no montante de recursos destinados à educação, além de facilitar a participação social 


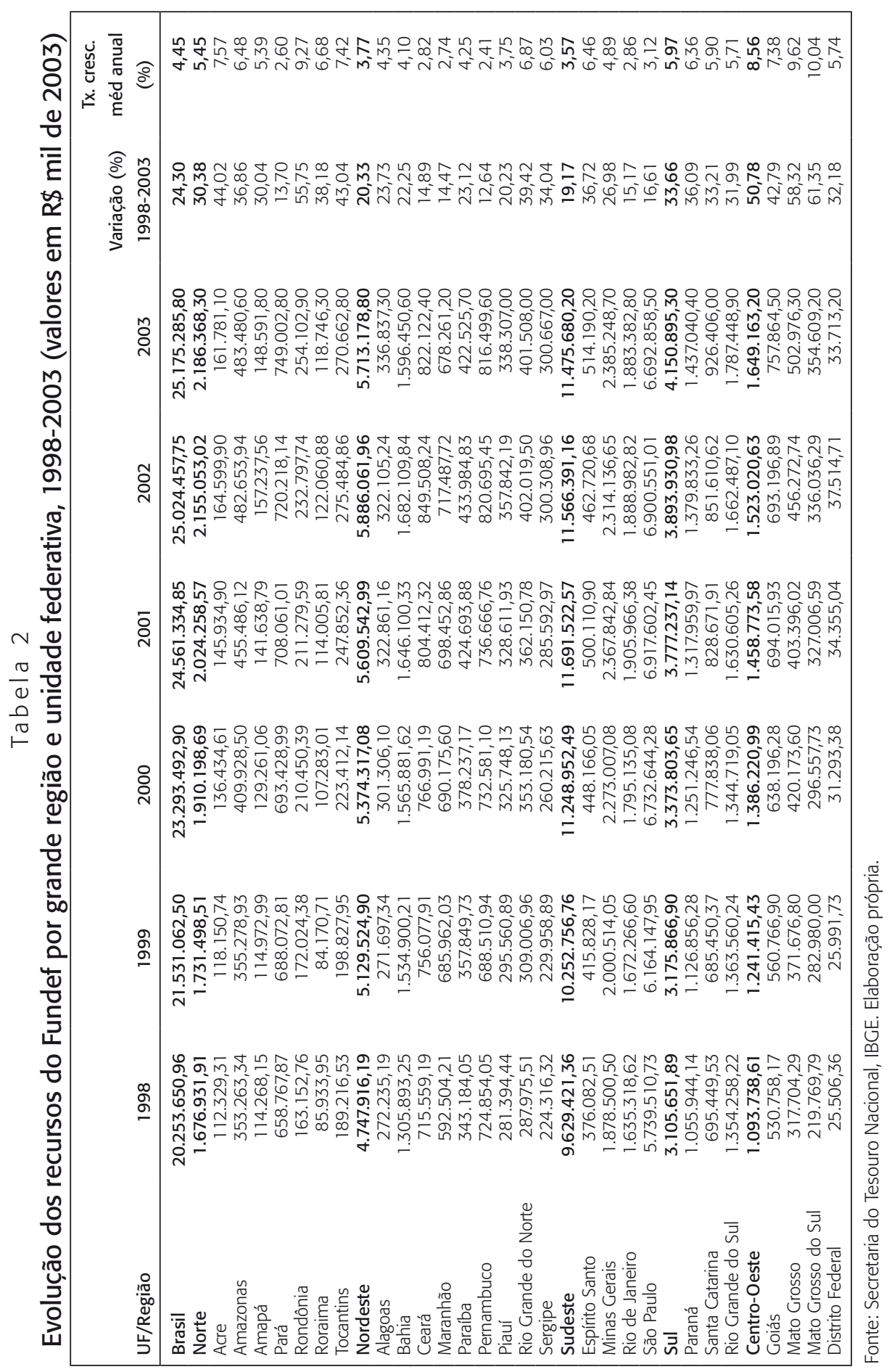


no acompanhamento da aplicação dos mesmos. Pode-se dizer que um dos maiores méritos do Fundef se relaciona ao fato de que o investimento em educação pública fundamental passa a obedecer a critérios econômicos, e não políticos. Embora não se discuta que o montante de recursos investido no ensino público brasileiro ainda se encontra distante do desejável, é possível argumentar que a ampliação dos investimentos possibilitada com o Fundef contribui para a melhoria dos indicadores de qualidade da educação.

\section{Indicadores de qualidade do ensino público fundamental}

A hipótese de que a proficiência do aluno pode ser diretamente influenciada pelo ambiente escolar é cada vez mais aceita, não só por educadores, mas por toda a sociedade. A dúvida que emerge dessa constatação remete à questão do quão importante são os recursos financeiros para a formação de uma escola de qualidade. Ainda que nem todas as virtudes de uma boa escola - como a harmonia entre pais, alunos e professores - possa ser obtida com esses recursos, a importância dos mesmos na construção de um ambiente profícuo à aprendizagem é fundamental.

A capacidade do Fundef de ampliar o potencial cognitivo dos alunos da rede pública foi medida por Menezes-Filho e Pazello (2004). Usando resultados dos estudantes em exames das Saeb (sinopses estatísticas da educação básica), esses autores confirmaram a significância de variáveis de infra-estrutura escolar, assim como a remuneração de professores e diretores, na melhora das notas dos alunos. Foram consideradas também a experiência dos professores e a escolaridade dos pais na análise. Os efeitos da melhora nas rendas escolares repercutiram, especialmente, em escolas municipais do Nordeste, desde a implementação do Fundef.

As tabelas 3 e 4 retratam, respectivamente, o desempenho dos alunos da $4^{\mathrm{a}}$ e $8^{\mathrm{a}}$ séries nos exames das Saeb realizados em 1997, 1999, 2001 e 2003. As tabelas trazem a nota média nos exames de língua portuguesa e matemática dessas avaliações que, a cada dois anos, medem a proficiência dos estudantes brasileiros. 
Enquanto as notas médias da $4^{a}$ série em todo o Brasil (tabela 3) caíram de 179,3 pontos para 164,5 pontos na rede municipal $(-8,3 \%)$, e de 185,1 pontos para 173,8 pontos na rede estadual $(-6,2 \%)$, a rede privada registrou uma redução de 227,8 pontos para 219,2 pontos $(-3,8 \%)$. Ou seja, em 2003, a nota média dos alunos desta última rede era $26,12 \%$ maior que a nota média da rede estadual e $33,25 \%$ maior que a média da rede municipal.

Situação análoga é percebida nos resultados da $8^{\mathrm{a}}$ série (tabela 4). Nas escolas privadas, a média dos alunos brasileiros entre 1999 e 2003 caiu-0,9\%, passando de 293,9 pontos no primeiro ano para 291,3 pontos no último. Nas escolas estaduais a redução foi de $-4 \%$ (de 242,2 pontos para 232,7 pontos); ao passo que nas escolas municipais a queda foi de $-5,2 \%$ (de 240,5 pontos para 227,9 pontos). Entre as unidades da federação, a supremacia das notas dos estudantes da rede privada é confirmada em todos os anos analisados. Nota-se, também, que a diferença nos desempenhos vem aumentando, visto que as reduções percentuais entre os dois anos extremos da análise são menores na rede privada que nas redes públicas.

Percebe-se um cenário preocupante em relação ao desempenho dos alunos do ensino fundamental brasileiro nos últimos anos, a julgar que as notas médias nos exames das Saeb decaíram ao longo do intervalo 1998-2003. Na próxima seção é apresentado um exercício econométrico que correlaciona o desempenho nos exames com o gasto público em educação fundamental neste período. Os resultados confirmam a hipótese de que a qualidade do ensino oferecido é sensível aos investimentos em educação, bem como à qualificação profissional do magistério.

\section{Financiamento da educação e aprimoramento do ensino}

Tomando as unidades federativas como unidade de análise, a tabela 5 apresenta os coeficientes de correlação entre os resultados nas Saeb e algumas variáveis quantitativas. Médias construídas a partir dos resultados médios nos exames de língua portuguesa e matemática, para cada unidade federativa, 

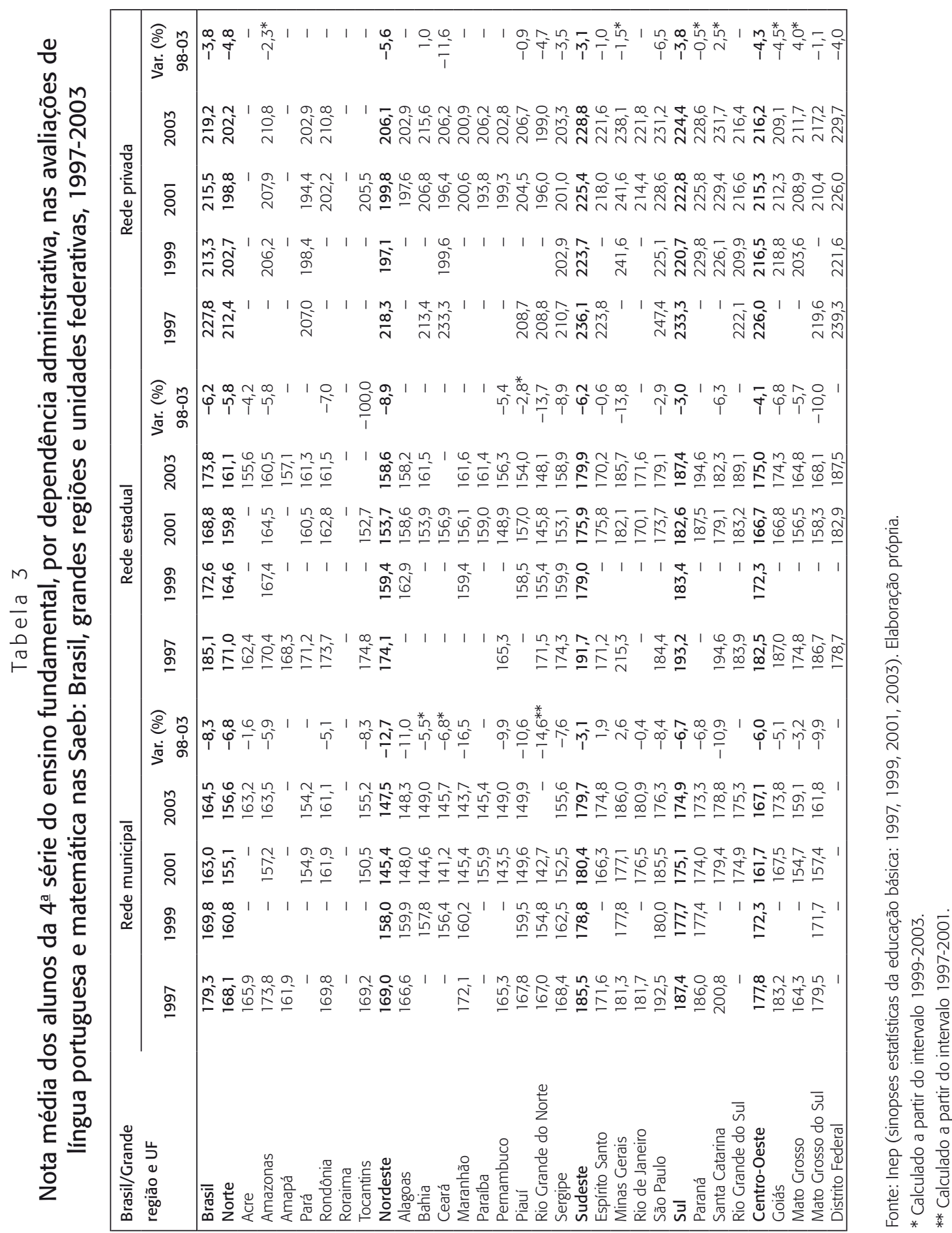


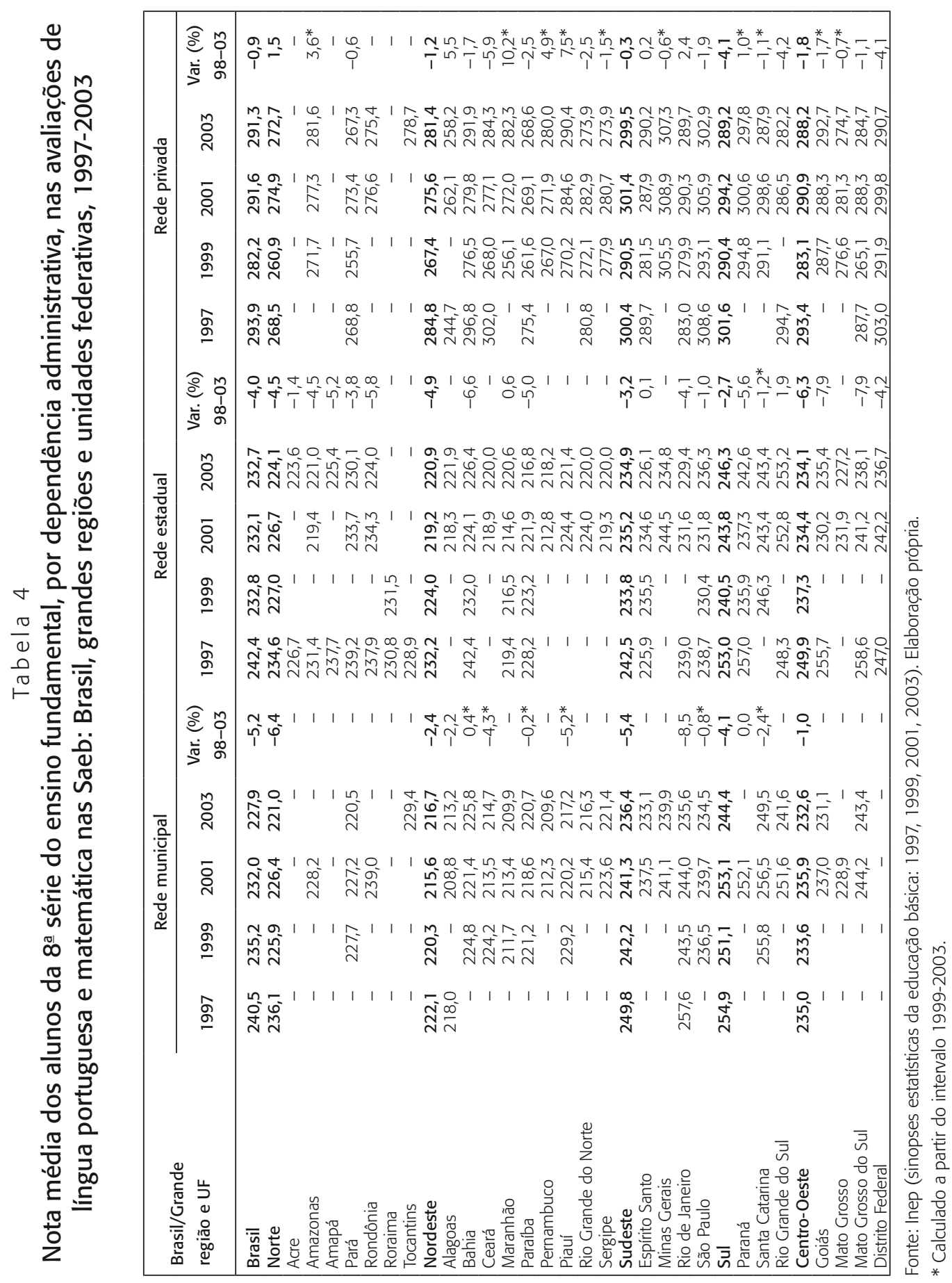


foram correlacionados com o gasto aluno/ano disponibilizado pelo Fundef, com a remuneração potencial média dos professores, ${ }^{7}$ também disponibilizada pelo Fundef, e com a proporção de professores com curso superior em relação ao total de matrículas. Os coeficientes foram correlacionados de acordo com a dependência administrativa dos alunos (estadual e municipal).

Os resultados apontam para correlações positivas entre o desempenho dos alunos nas avaliações e as três variáveis sugeridas. A correlação é mais forte entre as notas das Saeb e o gasto aluno-ano mínimo com o Fundef, ultrapassando os $80 \%$ em três ocasiões. Já os índices de correlação mais baixos são percebidos entre o desempenho nas avaliações e a remuneração potencial média dos professores. Mas, ainda assim, os índices foram positivos.

É possível detectar, também, que as correlações geralmente são maiores, para as três variáveis, quando se leva em conta os resultados das escolas municipais, sinalizando que os resultados destas são mais sensíveis à disponibilidade de recursos públicos ou à capacitação do corpo docente.

Complementando a análise será vista uma simulação com dados em painel que testa a influência dos gastos públicos em educação fundamental e da qualificação do professorado sobre o desempenho dos alunos da $4^{\mathrm{a}}$ série da rede pública de cada unidade federativa. A escassez de dados para todos os estados e para um intervalo de tempo maior comprometeu a elaboração de um exercício mais robusto. Simulação semelhante não pôde ser construída para os exames da $8^{a}$ série em virtude de dados faltantes. ${ }^{8} \mathrm{~A}$ tabela 6 exibe as estatísticas utilizadas para a construção do painel. Novamente, a nota média dos alunos foi construída levando-se em conta os resultados nas avaliações de língua portuguesa e matemática. As 19 unidades federativas foram selecionadas por serem as únicas a apresentar abrangência de dados nos três períodos estudados.

A análise de dados em painel, ou longitudinal, consiste basicamente na avaliação conjunta de dados em cortes transversais (cross section) observados também no tempo (séries temporais).

\footnotetext{
${ }^{7}$ Uma vez que a legislação do Fundef dispõe que $60 \%$ do total de recursos do fundo deve ser direcionado para a remuneração do magistério, a remuneração potencial média foi construída dividindo-se tal valor pelo total de professores da unidade federativa.

${ }^{8}$ Conforme assinala Baltagi (1996:7), o problema de dados faltantes configura entre as principais limitações da análise de dados em painel.
} 
Tabela 5

Coeficientes de correlação*: resultados nas avaliações das Saeb versus gasto aluno-ano, remuneração potencial média dos professores e proporção de docentes com curso superior em 1999, 2001 e 2003

\begin{tabular}{|c|c|c|c|c|}
\hline & & Gasto aluno-ano & $\begin{array}{c}\text { Remuneração } \\
\text { méd. magistério }\end{array}$ & $\begin{array}{l}\text { Docentes com curso } \\
\text { superior/matrículas }\end{array}$ \\
\hline \multirow{4}{*}{$\begin{array}{l}\text { g } \\
\text { Бे }\end{array}$} & 4a Série municipal & 0,8210 & 0,5490 & 0,8973 \\
\hline & 4ạ Série estadual** & - & - & - \\
\hline & 8ミ Série municipal & 0,4930 & 0,4648 & 0,7135 \\
\hline & 8a Série estadual & 0,5781 & 0,2174 & 0,4453 \\
\hline \multirow{4}{*}{ ঠ্ণ } & 4a Série municipal & 0,8219 & 0,6432 & 0,6924 \\
\hline & 4a Série estadual & 0,6129 & 0,4049 & 0,4402 \\
\hline & 8ミ Série municipal & 0,8150 & 0,5096 & 0,8307 \\
\hline & 8ミ Série estadual & 0,5784 & 0,3017 & 0,6873 \\
\hline \multirow{4}{*}{ ֶֻ } & 4a Série municipal & 0,6234 & 0,4748 & 0,6278 \\
\hline & 4a Série estadual & 0,4407 & 0,2269 & 0,6435 \\
\hline & 8a Série municipal & 0,6557 & 0,5647 & 0,5524 \\
\hline & 8a Série estadual & 0,5606 & 0,3256 & 0,7123 \\
\hline
\end{tabular}

Fonte: Inep (Edudutabrasil), Secretaria do Tesouro Nacional. Elaboração própria.

* Os níveis de significância foram de pelo menos 10\%.

** O reduzido número de Ufs nesta amostra impediu a construção de coeficientes de correlação significativos.

No método utilizado, "mínimos quadrados generalizados" (generalized least squares), os termos constantes de cada indivíduo são aleatoriamente distribuídos ao longo de cada cross section componente do painel. Os interceptos abrigam, assim, um grupo de perturbações, análogas aos erros, a não ser pelo fato de que para cada grupo existe apenas uma regressão em cada período (Greene, 2000:567-569).

Tomou-se como variável dependente o logaritmo da nota média dos alunos das escolas públicas de cada estado nas avaliações de língua portuguesa e matemática, dentro das Saeb. As variáveis explicativas foram o logaritmo do gasto per capita anual com os alunos da rede pública, via Fundef, e a proporção de professores com diploma de curso superior em relação ao total de matrículas. ${ }^{9}$ A não-inclusão da variável de remuneração média do corpo docente deveuse a problemas de multicolinearidade com a variável de gasto per capita.

\footnotetext{
${ }^{9}$ Como já citado, a valorização do magistério está entre as prioridades do Fundef. Até 2001, o mecanismo de vinculação de receitas estimulava a capacitação de professores leigos, autorizando que parte dos recursos destinados à remuneração dos professores fosse direcionada para a complementação dos estudos dos mesmos.
} 


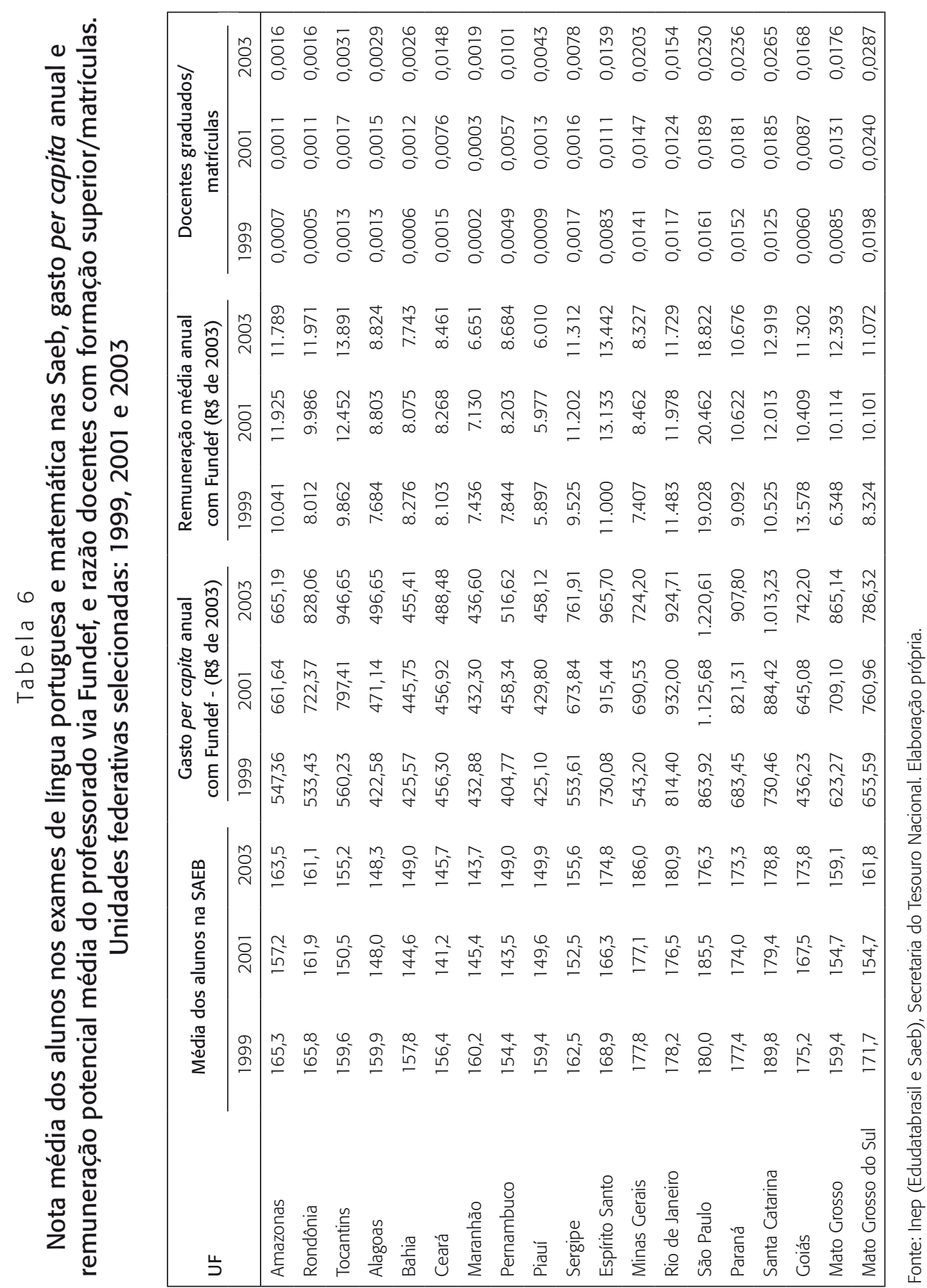


O software utilizado para a estimação foi o Eviews, e a estimação recorreu ao teste de White para covariância consistente (White heteroskedasticity consistent covariance) de forma a minimizar os efeitos heterocedásticos no modelo. O teste de hipótese para efeito de grupo foi significativo $(36,17)$, o que rejeita a hipótese de que os efeitos explicativos da variável dependente sejam os mesmos para todos os períodos da amostra (Baltagi, 1996). A escolha da estimação pelo modelo de efeitos aleatórios se deu em decorrência do teste de Hausman $(1,18)$.

Conforme mostra o quadro 2, o poder de explicação das variáveis independentes foi de $67,13 \%$ e o teste de Durbin-Watson rejeitou a hipótese de autocorrelação dos resíduos. O nível de significância das variáveis foi satisfatório num intervalo de confiança de $95 \%$, o que permite confirmar que os gastos anuais per capita (em logaritmo) sugere que um aumento de $0,15 \%$ nos gastos anuais por aluno no Fundef aumenta em 1\% a nota média nas provas de língua portuguesa e matemática nos exames das Saeb. A razão entre professores graduados e matrículas também influencia positivamente as notas dos alunos nos exames, com um coeficiente de 2,9.

Quadro 2

Resultado do painel

\begin{tabular}{|c|c|c|c|c|}
\hline \multicolumn{5}{|c|}{$\begin{array}{l}\text { Variável dependente: LN_SAEB? } \\
\text { Método: pooled least squares } \\
\text { Amostra: } 119 \\
\text { Observações incluídas: } 19 \\
\text { Total de observações do painel: } 57 \\
\text { White heteroskedasticity-consistent standard errors \& covariance }\end{array}$} \\
\hline Variável & Coeficiente & Desvio-padrão & t-statistic & Prob. \\
\hline LN_PERCAPITA? & 0,1581 & 0,027077 & 5,838902 & 0,0000 \\
\hline DOCENTES_SUP? & 2,8994 & 1,159620 & 2,500295 & 0,0153 \\
\hline \multicolumn{5}{|l|}{ Efeitos fixos } \\
\hline 99--C & 4,0998 & & & \\
\hline O1--C & 4,0186 & & & \\
\hline 03--C & 4,0121 & & & \\
\hline $\mathrm{R}^{2}$ & 0,6948 & \multicolumn{2}{|c|}{ Média da variável depend. } & 5,0914 \\
\hline $\mathrm{R}^{2}$ ajustado & 0,6713 & \multicolumn{2}{|c|}{ Desvio-padrão var. dep. } & 0,0774 \\
\hline SE da regressão & 0,0444 & \multicolumn{2}{|c|}{ Soma quadrado resíduos } & 0,1025 \\
\hline Log likelihood & 145,4877 & \multicolumn{2}{|l|}{ F-statistic } & 118,3799 \\
\hline Durbin-Watson stat. & 1,6781 & \multicolumn{2}{|c|}{ Prob. (F-statistic) } & 0,0000 \\
\hline
\end{tabular}

Fonte: Elaboração própria a partir de dados da Secretaria do Tesouro Nacional e das Saeb. (Inep). 
O teste serve para confirmar a intuição de que, quanto maiores os gastos em educação, maior o nível de aprendizagem dos alunos. Tal relação também poderia ser derivada a partir da comparação das notas médias de estudantes das redes pública e privada de ensino fundamental, apresentada na seção 4 . Assim, tomando-se por verdade que a qualidade do ensino público oferecido está aquém dos anseios da sociedade, não se pode deixar de se discutir a possibilidade de ampliação dos recursos destinados à educação, problema ainda não mitigado com o Fundef.

\section{Considerações finais}

De acordo com Helene e colaboradores (2001:119), os gastos totais com educação do Brasil são da ordem de 4,44\% do PIB, o que mantém o país não muito longe do padrão de gastos de países ricos, como os da OCDE, que aplicam em média $4,9 \%$ do PIB. O problema é que como a dimensão da economia brasileira está bem abaixo da dimensão desses países, o gasto per capita em educação aqui praticado é consideravelmente menor que nos países desenvolvidos. Enquanto nos Estados Unidos, por exemplo, são gastos aproximadamente US\$ 7 mil anuais por aluno (25\% da renda per capita daquele país), no Brasil as despesas anuais por estudante são de aproximadamente $\mathrm{R} \$ 900$ (cerca de $12 \%$ da renda per capita).

Essa constatação já serviria de sinalizador para a necessidade de se ampliar os gastos em educação no Brasil, em termos relativos e absolutos. No caso específico da educação fundamental, é necessário primeiramente um esclarecimento sobre qual deve ser o direcionamento das políticas no país - se voltadas para a criação de novas vagas e/ou para o aprimoramento da qualidade da educação já oferecida.

Levantamentos como o do Inep (2004) apontam que a cobertura da educação fundamental no Brasil registrou considerável ascensão nos últimos anos e, ainda que localidades específicas possam apresentar déficits no número de vagas, em linhas gerais o país parece estar próximo da cobertura integral. Considerando que o número de matrículas no ensino fundamental vem diminuindo, seja por efeito da transição demográfica em curso no país (Bloom, Canning e Sevilla, 2002) ou da queda nos índices de repetência, é importante passar a enfocar melhorias na qualidade do ensino público oferecido. O ideal seria que as escolas públicas de ensino fundamental aproveitassem essa diminuição gradativa na demanda por vagas para aumentar, também 
gradativamente, a permanência diária de estudantes na escola até atingir a jornada integral.

Este artigo mostrou que o esforço brasileiro para assegurar a descentralização e sustentabilidade do ensino fundamental tem seus méritos consubstanciados na implementação do Fundef, em vigor desde 1998. Mas também deixou explícito que a qualidade da educação oferecida nesse nível inspira cuidados. O desempenho dos alunos em exames de proficiência tem demonstrado declínio nos últimos anos, e o investimento público é importante instrumento para a reversão desse quadro.

\section{Referências bibliográficas}

BALTAGI, B. H. Econometric analysis of panel data. Chichester: John Wiley \& Sons, 1996.

BLOOM, D. E.; CANNING, D.; SEVILLA, J. The demographic dividend: a new perspective on the economic consequences of population change. Rand Publications, 2002. Disponível em: <www.rand.org/publications/MR/MR1274>. Acesso em: 3 set. 2004.

BRASIL. Constituição de 1988. Brasília: Câmara dos Deputados, 1995.

. Lei n. 424, de 24 de dezembro de 1996. Dispõe sobre o Fundo de Manutenção e Desenvolvimento do Ensino Fundamental e de Valorização do Magistério, na forma prevista no art. 60, parágrafo 7, do Ato das Disposições Constitucionais Transitórias e dá outras providências. Diário Oficial da União, 26 dez. 1996. Disponível em: <www6.senado.gov.br/legislacao>. Acesso em: 10 mar. 2005.

. Fundo de Manutenção e Desenvolvimento do Ensino Fundamental e de Valorização do Magistério. Manual de orientação. Brasília, 2004. 83 p. ms.

CAMPOS, B. C.; SOBREIRA, R. O Fundef e seus impactos no financiamento da educação pública fundamental no Brasil. In: ENCONTRO NACIONAL DE ECONOMIA POLÍTICA DA SEP (Enep), 10., 2005, Campinas. Anais... Campinas, SP, 2005.

CASTRO, J. A. O Fundo de Manutenção e Desenvolvimento do Ensino Fundamental e Valorização do Magistério (Fundef) e seu impacto no financiamento do ensino fundamental. Ipea, 1998. (Texto para Discussão n. 604).

GREENE, W. H. Econometric analysis. New Jersey: Prentice Hall, 2000. 
HELENE, O. A. M.; BEZERRA, P. L.; FONSECA FILHO, R. Relatório do Grupo de Trabalho sobre Financiamento da Educação. Revista Brasileira de Estudos Pedagógicos. Brasília, v. 82, n. 200-202, p. 117-136, jan./dez. 2001.

INEP. Os desafios do plano nacional de educação. MEC/Inep. Disponível em: <www. inep.gov.br/download/cibec/2004/pne/pne01.pdf>. Acesso em: 16 dez. 2004.

MENEZES FILHO, N.; PAZELLO, E. Does money in schools matter? Evaluating the effects of Fudef on wages and test scores in Brazil. Seminários 2004: EPGE/FGV, 2004.

NEGRI, B. O Fundo de Manutenção e Desenvolvimento do Ensino Fundamental e de Valorização do Magistério. Inep, 1997a. (Texto para Discussão).

. O financiamento da educação no Brasil. Inep, 1997b. (Texto para Discussão). 